\title{
Cardiac risk in the treatment of breast cancer: assessment and management
}

\author{
This article was published in the following Dove Press journal: \\ Breast Cancer:Targets and Therapy \\ 16 January 2015 \\ Number of times this article has been viewed
}

\author{
Antonis Valachis' \\ Cecilia Nilsson ${ }^{2}$ \\ 'Centre for Clinical Research \\ Sörmland, Uppsala University, \\ Eskilstuna, Sweden; ${ }^{2}$ Center for \\ Clinical Research, Västmanlands \\ County Hospital, Västerås, Sweden
}

Correspondence: Antonis Valachis Department of Oncology, 63188 Mälarsjukhuset, Eskilstuna, Sweden $\mathrm{Tel}+46735617691$ Fax +46 I6 I04 035 Email valachis@hotmail.com; antonis. valachis@onkolog.uu.se

\begin{abstract}
As the number of long-term breast cancer survivors has increased, the side effects of adjuvant cancer therapy, such as cardiac toxicity, remain clinically important. Although the cardiac toxicity due to anthracyclines, radiotherapy, or trastuzumab is well-documented, several issues need to be clarified and are the subjects of extensive ongoing clinical research. This review summarizes the incidence of cardiac toxicity due to breast cancer adjuvant therapy and highlights the current trends in early detection and management of cardiac toxicities.
\end{abstract}

Keywords: adjuvant, anthracyclines, cardiac toxicity, radiotherapy, trastuzumab

\section{Introduction}

Breast cancer is the most common cancer in women worldwide, with nearly 1.7 million new cases diagnosed in 2012. ${ }^{1}$ The advances in the diagnosis and treatment of breast cancer have led to an improved outcome and a large proportion of long-term breast cancer survivors. It is estimated that nearly $90 \%$ of women diagnosed with breast cancer will survive for 5 years or longer. ${ }^{2}$

The cornerstone of breast cancer therapy is surgery. It is well documented that many patients with early breast cancer benefit from postoperative adjuvant therapy (radiotherapy, chemotherapy, targeted therapy, or endocrine therapy), a treatment strategy with a view to eradicate distant micrometastatic deposits. The choice of appropriate adjuvant therapy is based on the stage of the disease, the functional status and comorbid condition of the patient, and the clinicopathological and molecular characteristics of the tumor. Several adjuvant therapies against breast cancer can potentially cause a wide range of acute and late cardiac complications. This subject is of rising concern considering the increased number of long-term breast cancer survivors and the trend to combine two or more potentially cardiotoxic therapies in the adjuvant setting.

The goal of this review is to summarize the current knowledge on the incidence of cardiac toxicity in different adjuvant breast cancer therapies and highlight the current trends in early detection and management of cardiac toxicities. This review is focused on well-established and widely used adjuvant therapies (radiotherapy, chemotherapy, anti-human epidermal growth factor 2 (anti-HER2) therapy) and not on experimental therapies.

\section{Radiotherapy-induced cardiac toxicity in early breast cancer}

Adjuvant radiotherapy is recommended in most of the patients undergoing breast cancer surgery. Adjuvant whole breast radiotherapy after breast-conserving surgery 
reduces the risk of local recurrences by about two-thirds. ${ }^{3}$ In cases of mastectomy, radiotherapy is recommended for all patients with node-positive disease, and in T3-T4 disease radiotherapy is recommended irrespective of nodal status. ${ }^{4}$ In node-positive patients, radiotherapy reduces the risk of breast cancer mortality and increases overall survival; ${ }^{5}$ for these patients, approximately one breast cancer death is avoided for every 1.5 recurrences of any type after radiotherapy.

However, a major concern when radiotherapy is administered in patients with early breast cancer with an expected long-term survival is the unintentional irradiation of adjacent organs. Several studies demonstrate an excess of cardiac deaths after longer follow-up that partly counterbalance the decrease in breast cancer death. ${ }^{6-8}$

The underlying pathophysiological mechanisms of radiation-induced heart disease (RIHD) are related to micro- and macrovascular damage, which leads to clinical manifestations such as pericarditis, coronary artery disease, acute myocardial infarction, valvular heart disease, and cardiomyopathy. ${ }^{9}$ Most data regarding the risk of cardiac morbidity and mortality subsequent to radiotherapy comes from retrospective population-based studies that have compared cardiac outcome after left- versus right-sided breast irradiation. In an analysis from the US Surveillance, Epidemiology, and End Results (SEER) database that includes patients treated during the period 1973-2001, a significantly increased risk of cardiac mortality was seen after left-side irradiation. ${ }^{10,11}$ Similar results have been seen in two other studies that included patients during the periods 1954-1984 and 1977-1994. ${ }^{8,12}$ In all of these studies which entail long time periods, a non-negligible portion of patients were treated with older radiotherapy techniques, which were often associated with high mean radiation doses to the heart. The cardiac side effects of contemporary radiotherapy are less investigated since a long follow-up is essential to reveal clinically significant RIHD. Nonetheless, in the above-mentioned SEER analysis, different time periods were compared and the results indicated a reduction in cardiac morbidity during the latest time period when more modern radiation techniques were implemented. ${ }^{11}$

This decrease in cardiac morbidity according to time period could also reflect an increased knowledge about important parameters in breast radiotherapy, such as the mean radiation dose. Recently, Darby et al demonstrated that the risk of major coronary events increased linearly with the mean radiation dose to the entire heart. This increased risk was observed as soon as 5 years after radiotherapy had been completed and continued for 3 decades. ${ }^{13}$ Similarly, studies have investigated cardiac radiation doses in left-side breast or chest wall irradiation during different time periods and have revealed a considerable decrease in whole heart doses over the past decades. ${ }^{14-16}$

In some recent guidelines, the entire heart is considered as an organ at risk with defined radiation dose limits. Nevertheless, the heart consists of different structures, probably with different levels of radiation tolerance. Furthermore, the dose distribution in the heart during tangential whole breast radiotherapy is inhomogeneous, with higher doses delivered to the anterior part of the heart. Nilsson et al demonstrated a four- to sevenfold increased risk of stenosis in coronary arteries in areas with hot spot radiation doses; the increased risk was observed mainly to the left anterior descending artery (LAD). ${ }^{16}$ Similarly, Correa et al demonstrated a significantly higher prevalence of coronary artery abnormalities after left-breast irradiation compared with right-breast irradiation, with $70 \%$ of the abnormalities occurring in the LAD. ${ }^{17}$ These findings emphasize the importance of trying to avoid high radiation doses in any part of the heart, especially in the coronary arteries. Therefore, current guidelines recommend that the coronary arteries should be regarded as separate organs at risk. ${ }^{18}$

The most important factor influencing the dose to the heart is the target volume. In node-negative patients undergoing radiotherapy of the breast/chest wall with tangential fields, the dose to the heart is, as a rule, low. ${ }^{19}$ However, it is difficult to protect the heart from irradiation when the regional lymph nodes are included in the radiation field. Irradiation of the internal mammary chain (IMC), in particular, often leads to high cardiac doses and has been demonstrated to significantly increase the rate of RIHD. ${ }^{7,12}$ Recently, two published randomized trials evaluating the benefit of IMC irradiation on overall survival demonstrated a modest survival benefit when radiotherapy in the regional nodes including the IMC was administered. ${ }^{20,21} \mathrm{~A}$ third randomized trial investigating the same research question could not reveal any survival benefit but the study was underpowered to detect such differences. ${ }^{22}$ Because this benefit seems to be limited and the risk for RIHD after IMC irradiation does exist, it is important to explore the benefit/risk ratio and individualize the treatment decision until further data from randomized trials are available.

Several modern radiation techniques have been introduced with the aim of reducing the radiation dose to the heart. Modern 3D conformal radiotherapy planning most often enables high target-volume coverage with estimated low radiation dose to the whole heart, but it is difficult to reduce the dose to the anterior part of the heart to non-harmful 
levels without compromising treatment effect. ${ }^{19}$ Active breathing control is a method which helps patients to reproducibly perform breath-holding during radiotherapy with the aim of delivering radiotherapy after inspiration when the heart is farthest from the irradiation. The use of active breathing control significantly reduces the dose to the whole heart and the proximal part of the LAD, but there appears to be a risk of an increase in dose in the caudal part of the LAD. ${ }^{23,24}$ Intensity-modulated radiotherapy (IMRT) has been demonstrated to further reduce the maximal dose to the heart, especially in patients with unfavorable cardiac anatomy. ${ }^{23}$ The use of volumetric modulated arc therapy, namely rotational IMRT, seems to further reduce the heart dose in patients treated with locoregional radiotherapy of left-sided breast cancer. ${ }^{25}$ Recently, the use of proton therapy (intensity-modulated proton therapy) instead of IMRT that uses photon-based radiation has been investigated in terms of heart doses. The use of intensity-modulated proton therapy significantly decreased the radiation dose to the heart and LAD compared with IMRT with breath-hold technique. ${ }^{26}$ Whether this decreased dose is clinically relevant for the patients needs to be determined in further studies.

When estimating the risk-benefit of radiotherapy in the individual patient, it is also important to consider other factors that increase the risk of RIHD, such as smoking, diabetes, or a history of ischemic heart disease. ${ }^{12,13}$ The only way of totally avoiding the risk of RIHD is to omit radiotherapy. However, as previously described, radiotherapy significantly increases breast cancer-specific survival and overall survival in most patients, but studies have demonstrated that it can be a safe to omit radiotherapy in older patients with low-risk breast cancer. ${ }^{27}$

\section{Chemotherapy-induced cardiac toxicity in early breast cancer Anthracycline-based chemotherapy}

Anthracycline-based regimens, including epirubicin or doxorubicin, have been the cornerstone of breast cancer chemotherapy in both adjuvant and metastatic settings. ${ }^{28}$ A well-documented side effect of anthracyclines is cardiac toxicity. ${ }^{29}$ The most common manifestation of anthracyclineinduced cardiotoxicity is left ventricular dysfunction that may be systolic or diastolic, asymptomatic or symptomatic.

Although anthracycline-related cardiotoxicity is a wellknown adverse effect, its underlying mechanism remains to a large extent unknown. The hypothesis on the role of oxygen free radicals that could lead to irreversible damage in myocardiocytes has been called into question since it does not seem to explain the whole mechanism. ${ }^{29}$ Recently, a molecular hypothesis has been proposed in which anthracycline impairs DNA repair pathways through the interaction with the topoisomerase-II-beta enzyme in myocytes. ${ }^{30}$

Anthracycline-related cardiac toxicities represent an irreversible form of chemotherapy-related cardiac dysfunction (CRCD), referred to as type I CRCD. ${ }^{31}$ This type of CRCD is different from the cardiac toxicity caused by trastuzumab which will be discussed later in this review. A recent metaanalysis revealed a 5.4-fold increased risk of clinical cardiotoxicity, 6.3-fold increased risk of subclinical cardiotoxicity, and a fivefold increased risk of cardiac death among cancer patients treated with anthracyclines compared to those treated with non-anthracycline-based regimens. ${ }^{32}$

Several risk factors have been associated with an increased risk for anthracycline-related cardiac toxicity, with the most robust to be the cumulative dose ${ }^{33}$ For doxorubicin, the estimated percentage of patients with doxorubicin-related heart failure was found to be $5.0 \%$ at a cumulative dose of $400 \mathrm{mg} / \mathrm{m}^{2}, 26.0 \%$ at $550 \mathrm{mg} / \mathrm{m}^{2}$, and $48.0 \%$ at $700 \mathrm{mg} / \mathrm{m}^{2} .{ }^{34}$ Likewise for epirubicin, the risk of cardiotoxicity increased from $1.9 \%$ at doses of $800 \mathrm{mg} / \mathrm{m}^{2}$ to $4.3 \%$ at doses of $900 \mathrm{mg} / \mathrm{m}^{2}$ and $15.0 \%$ at doses of $1,000 \mathrm{mg} / \mathrm{m}^{2} .{ }^{35}$ These observations have led to the adoption of thresholds on the accepted cumulative dose of anthracyclines in treated patients. These thresholds are differed between epirubicin and doxorubicin since, at equimolar doses, epirubicin is less cardiotoxic than doxorubicin because of the lower levels of secondary alcohol metabolites that are produced from epirubicin. ${ }^{36} \mathrm{In}$ the previously mentioned meta-analysis, the authors found that the use of epirubicin significantly decreased the risks of both clinical and subclinical cardiotoxicity. ${ }^{32}$ However, recent evidence indicates that anthracycline-related cardiotoxicity may occur even in lower cumulative doses, especially among patients with preexisting cardiovascular risk factors, and therefore no safe threshold does exist. ${ }^{37}$ Consequently, in patients with anthracycline-based therapy, it is essential to take into account other classical risk factors for cardiac toxicity as well, such as the age at the time of drug exposure, concomitant administration of other cardiotoxic chemotherapeutic agents (trastuzumab), concurrent or prior chest irradiation, and preexisting cardiovascular disease (including coronary artery disease, hypertension, peripheral vascular disease, diabetes). ${ }^{37}$

Based on the well-recognized risk factors for anthracycline-related cardiotoxicity, a variety of approaches have been considered to decrease the risk of cardiotoxicity while maintaining efficacy. These include the limitation of the total 
cumulative dose, alterations in schedules of drug administration, ${ }^{38}$ modifications of the anthracycline molecule (liposomal anthracyclines), ${ }^{39}$ administration of non-anthracycline-based chemotherapy without jeopardizing survival, and use of adjunctive cardioprotective treatment with dexrazoxane. ${ }^{38}$

Infusional administration of anthracyclines over 6 hours or more may lower the incidence of cardiotoxicity compared to bolus therapy. A Cochrane review of five randomized controlled trials found that continuous infusion of 6 hours or longer significantly reduced the risk of clinical heart failure (and probably also subclinical cardiac damage) when compared with infusions of 1 hour or less. ${ }^{38}$ There was no evidence that continuous infusion reduced response rate or survival. Despite these observations, the continuous infusion has several drawbacks (need for hospitalization and central venous catheters, questionable cost-effectiveness) that limit its clinical use.

Encapsulation of doxorubicin into liposomes significantly reduces its distribution volume, diminishing its diffusion and consequently, the toxicity for healthy tissues. ${ }^{39}$ In the previously mentioned meta-analysis, liposomal compared to conventional doxorubicin significantly decreased the risk of clinical and subclinical cardiotoxicity. ${ }^{32}$ However, all the studies included in the meta-analysis investigated the role of liposomal doxorubicin in patients with metastatic breast cancer. The role of liposomal doxorubicin in the adjuvant setting is still under investigation. Early Phase II trials have found that liposomal doxorubicin seems to be a feasible option for elderly patients, ${ }^{40}$ and in concurrent administration with trastuzumab ${ }^{41}$ as adjuvant treatment. Several randomized trials with the aim of investigating the efficacy and safety of liposomal doxorubicin in elderly early breast cancer populations are ongoing. Advances in the liposome formulation, with the use of cross-linked multilamellar liposome, have been recently published and showed, in in vivo experiments, a reduced systemic toxicity and improved anticancer activity compared to currently used liposomal doxorubicin. ${ }^{42}$ This new formulation has the ability to incorporate two different chemotherapeutic agents into the same liposome (doxorubicin and paclitaxel) to reduce the toxicity and increase the synergistic effect. ${ }^{43}$ Further studies on this new liposome formulation are warranted.

Dexrazoxane is an iron-chelating agent that is thought to decrease the cardiotoxic effect of doxorubicin by blocking the generation of free radicals. In a meta-analysis of six randomized trials, of which only three examined dexrazoxane use in a homogenous breast cancer population receiving initial anthracycline-based therapy, dexrazoxane given with either doxorubicin or epirubicin significantly reduced the incidence of clinical and subclinical cardiotoxicity. However, there was a nonsignificant trend toward lower response rates among those who received anthracycline plus dexrazoxane. ${ }^{38}$ Considering the lack of clinical data on dexrazoxane in the adjuvant setting and the concerns about potential impact on antitumor efficacy, dexrazoxane is not recommended for use in early breast cancer.

Finally, avoidance of anthracycline-based chemotherapy in the adjuvant setting is a certain strategy to reduce anthracycline-associated cardiotoxicity. Recently, the triplet docetaxel-carboplatin-trastuzumab was proved to be as effective as the anthracycline and taxane-based standard of care chemotherapy with less cardiac events, and it offers a valuable alternative in patients with human epidermal growth factor 2 (HER2) early breast cancer. ${ }^{44}$

\section{Addition of taxanes}

The addition of taxanes to anthracycline-based chemotherapy as adjuvant therapy reduces the risk of recurrence and overall mortality by $4.6 \%$ and $3.2 \%$, respectively. ${ }^{45}$ Thus, it is considered standard of care in the adjuvant setting. In early studies, concerns were raised about the higher risk for bradycardia and cardiac arrhythmias with paclitaxe ${ }^{46}$ as well as higher risk for left ventricular diastolic dysfunction with docetaxel ${ }^{47}$ However, studies with a large number of patients did not confirm these results. ${ }^{48}$

Paclitaxel seems to interfere with the metabolism and excretion of anthracycline metabolites that contribute to the mechanism of cardiac toxicity. ${ }^{49}$ Indeed, the combination of bolus doxorubicin and paclitaxel resulted in an unacceptably high risk of cardiac complications. ${ }^{50}$ On the contrary, the combination of epirubicin and paclitaxel was feasible with respect to cardiac toxicity as long as the cumulative dose of epirubicin did not exceed the threshold of $990 \mathrm{mg} / \mathrm{m}^{2} .^{51}$

Modern adjuvant regimens including taxanes do not increase the anthracycline cardiotoxicity as has been clearly shown in a meta-analysis of recent randomized trials. ${ }^{52}$ Conversely, taxane schemes that contain less anthracycline than control arms were associated with less cardiovascular toxicity. ${ }^{52}$

\section{Endocrine therapy: does it negatively affect cardiac function?}

Adjuvant endocrine therapy in estrogen receptor-positive early breast cancer significantly reduces the risk of breast cancer recurrence and improves overall survival. ${ }^{53-55}$ Tamoxifen is the recommended treatment in premenopausal 
women, whereas aromatase inhibitors (AI) have demonstrated superiority compared with tamoxifen in postmenopausal women. ${ }^{54-56}$ Tamoxifen is a selective estrogen receptor modulator with both antagonistic and agonistic estrogen properties. AI (anastrozole, letrozole, exemestane) exert their effect by blocking the conversion of androgens to estrogens and thereby reducing levels of estrogen in plasma and tissue. ${ }^{57}$ It has been hypothesized that this interference in the normal estrogen system could influence the risk of cardiovascular disease.

Tamoxifen has been shown to reduce plasma levels of low-density lipoprotein cholesterol, which in other circumstances has been associated with a decrease in the risk of cardiovascular events. ${ }^{58}$ In a meta-analysis evaluating tamoxifen and focusing on adverse effects, tamoxifen was associated with a decreased risk of death from myocardial infarction although no impact on the incidence of myocardial infarction was observed. ${ }^{59}$ However, in the meta-analysis by the Early Breast Cancer Trialists' Collaboration Group, no significant reduction in cardiovascular mortality was demonstrated. ${ }^{53}$ In contrast to tamoxifen, treatment with AIs has been associated with increased levels of cholesterol, ${ }^{54,56}$ which has led to a fear of an increased risk of cardiovascular adverse events. In the pivotal trial for anastrozole, patients were randomized between anastrozole, tamoxifen, or a combination of both. No significant difference in cardiovascular deaths between the groups was observed but anastrozole treatment was associated with an increase in mild to moderate angina and hypertension. ${ }^{60}$ In another trial, 5 years of treatment with letrozole were compared with tamoxifen or sequential treatment with both substances. After a median follow-up of 51 months, patients treated with letrozole had a higher incidence of cardiac events grade 3-5, cardiac failure grade 3-5, and peripheral atherosclerotic events. ${ }^{61}$ Similar results were seen in a study evaluating tamoxifen or tamoxifen in sequence with exemestane, in which the treatment group with exemestane had significantly more ischemic cardiac adverse events after a median follow-up of 91 months. ${ }^{62}$ On the other hand, no increased risk of cardiovascular adverse events with AI could be observed in a large trial evaluating prolonged treatment with letrozole or tamoxifen after completion of 5 years tamoxifen treatment. ${ }^{63}$

In summary, AI seem to entail a minor increase in the risk of cardiac adverse events whereas tamoxifen does not seem to entail any cardiac risks. In most patients, this potential risk of cardiovascular adverse events with AI is outweighed by the treatment's significant improvement in breast cancer survival. When choosing treatment for the individual patient, it is also important to consider other side effects of the different treatments; these have been discussed elsewhere. ${ }^{53-56}$

\section{Anti-HER2-induced cardiac toxicity}

Trastuzumab, a humanized anti-HER2 monoclonal antibody, is the standard of care in patients with HER2-positive breast cancer in any treatment setting. The importance of trastuzumab in HER2-positive breast cancer disease was first demonstrated in the metastatic setting, in which trastuzumab changed the natural history of HER2-positive disease from a clinical entity with poor prognosis (patients with HER2positive breast cancer had the worst prognosis among breast cancer patients) to a disease with comparable or even better outcome than HER2-negative disease. ${ }^{64}$ In the adjuvant setting, 1-year treatment with trastuzumab offers substantial benefit in terms of both disease-free and overall survival. ${ }^{65}$

Trastuzumab was first approved in 1998 for the treatment of HER2-positive metastatic breast cancer, and cardiac dysfunction was recognized early on as a potential toxicity of trastuzumab. ${ }^{66}$ In the early pivotal trials in the metastatic setting, the rates of cardiac dysfunction ranged from $8 \%$ to the unacceptably high rate of $30 \%$ in cases of concomitant administration of trastuzumab with anthracyclines. ${ }^{66}$ These findings had a major impact on the design of adjuvant trials in which strict cardiac exclusion criteria, prospective monitoring of cardiac function, interim cardiac safety analyses, as well as treatment schedules with sequential use of anthracyclines and trastuzumab instead of concomitant administration were adopted.$^{67}$ As a result, the cardiotoxicity rates in adjuvant randomized trials were lower than in metastatic ones (symptomatic congestive heart failure rate ranged between $0.8 \%$ and $14.2 \%) .{ }^{67}$ However, a significantly increased risk for both left ventricular ejection fraction (LVEF) decline and congestive heart failure was observed in the trastuzumab-treated arm. ${ }^{68}$ In the real-world setting, where the cardiac exclusion criteria are not as strict as those applied in the randomized controlled trials, the rate of cardiac toxicity is similar to the one observed in randomized clinical trials. ${ }^{69,70}$

The pathophysiological mechanisms underlying trastuzumab-related cardiotoxicity are not completely clear. Preclinical data have suggested an important role for the HER2 signaling pathways in cardiac physiology, given that both HER receptors and their ligands are expressed in the cardiomyocytes. ${ }^{71}$ The mechanisms of trastuzumab-induced cardiotoxicity differ substantially from those of anthracyclines. Trastuzumab-induced cardiotoxicity, as opposed to anthracycline-induced cardiotoxicity, is not dose dependent, is reversible upon therapy withdrawal, 
and the drug can be safely readministered after recovery of cardiac function. ${ }^{31}$ The cardiac toxicity due to trastuzumab is classified as type II CRCD. ${ }^{31}$ One potential mechanism of cardiotoxicity is the inactivation of a HER ligand-mediated pathway that leads to cell survival in case of adverse hemodynamics or other stress. ${ }^{72}$ This proposed mechanism could explain both the higher risk for cardiotoxicity when trastuzumab and anthracyclines are combined (the stress and damage caused by anthracyclines is increased) and the reversibility of cardiotoxicity with trastuzumab withdrawal (the pathway is becoming functional again). ${ }^{72}$

Several risk factors for trastuzumab-induced cardiotoxicity have been identified. ${ }^{67}$ The most important one is the concomitant administration with anthracyclines. It has been demonstrated that there is a clear effect of cumulative anthracycline dose and trastuzumab-induced cardiotoxicity. ${ }^{73-75}$ On the contrary, in the neoadjuvant setting, the concomitant administration of anthracyclines and trastuzumab, compared with sequential administration, was not correlated with higher risk for cardiac adverse events. ${ }^{76-78}$ However, in the absence of any difference in the pathologic complete remission with the concurrent administration of trastuzumab and epirubicin, ${ }^{78}$ and considering the concerns about the limited follow-up for cardiac events in these studies, ${ }^{76}$ this approach is not recommended as standard of care.

Advanced age has also been associated with an increased risk of trastuzumab-induced cardiotoxicity. ${ }^{74,79}$ Older patients appear to face a higher risk for cardiac toxicity due to trastuzumab, with higher rates than those reported in randomized clinical trials. ${ }^{80}$ Other potential risk factors are antihypertensive medications, ${ }^{79}$ borderline cardiac function at baseline, ${ }^{79}$ and a history of heart disease. ${ }^{81}$

Some efforts have been made to identify certain polymorphisms in the HER2 gene that could trigger cardiotoxicity. The polymorphism I655V in the HER2 gene has been associated with cardiac toxicity in three different research groups. ${ }^{82-84}$ As our knowledge about the mechanism of trastuzumab-induced cardiotoxicity increases, and with the help of genome-wide association studies, it is possible that pharmacogenomics will play an important role in the near future as an approach to identify patients at high risk for trastuzumab-induced cardiac toxicity.

Besides trastuzumab, two additional anti-HER2 agents have been developed and approved for the treatment of HER2positive breast cancer: the tyrosine kinase inhibitor lapatinib is approved in metastatic setting ${ }^{85}$ and the monoclonal antibody pertuzumab is approved in the neoadjuvant and metastatic setting. ${ }^{86,87}$ Recently, a new treatment option for
HER2-positive breast cancers consisting of the combination of two anti-HER2 agents has been evaluated. Lapatinib in combination with trastuzumab has shown promising results as neoadjuvant ${ }^{88}$ and metastatic treatment, ${ }^{89}$ while pertuzumab has been approved only in combination with trastuzumab both as neoadjuvant and as metastatic treatment. Those two anti-HER2 agents have also been associated with cardiac toxicity. ${ }^{85-87}$ There is, therefore, a concern regarding the potential risk for increased cardiac adverse events when two anti-HER2 agents that both increase cardiac toxicity are combined. However, a recent meta-analysis could not reveal any increased risk for cardiac toxicity with any of the combinations compared with monotherapy with one anti-HER2 agent. ${ }^{90}$ Several randomized trials investigating the role of dual anti-HER2 blockade in the adjuvant setting are ongoing.

\section{Assessment and monitoring of cardiac health in breast cancer patients with adjuvant therapy}

There are several recommendations and guidelines available for the assessment and monitoring of cardiac toxicity during and after breast cancer treatment. ${ }^{9,91-95}$ These recommendations are mainly based on expert consensus due to the paucity of available high-level evidence.

Two of the basic concepts that are common in all the guidelines are: the value of a careful case-by-case baseline evaluation of preexisting risk factors for cardiac adverse events and the need for an appropriate and well-structured cardiac monitoring during and after cancer therapy to identify patients with asymptomatic cardiac dysfunction, so that breast cancer treatments can be modified and cardiac medication can be started.

Table 1 presents a summary of recommendations and areas of active research regarding assessment, monitoring, and treatment of cardiac toxicity due to cancer therapy in patients with early breast cancer.

\section{Baseline assessment/evaluation}

The purpose of the baseline evaluation is to identify patients with high risk for cardiac toxicity due to cancer therapy. We discussed earlier in the review that several risk factors for cardiac toxicity during anticancer therapy have been identified. However, it is difficult to incorporate the baseline assessment in an algorithm for cardiac monitoring because of the lack of evidence about the strength of each risk factor in the estimation of cardiac risk. The only available cardiac risk score has been developed by investigators from the 


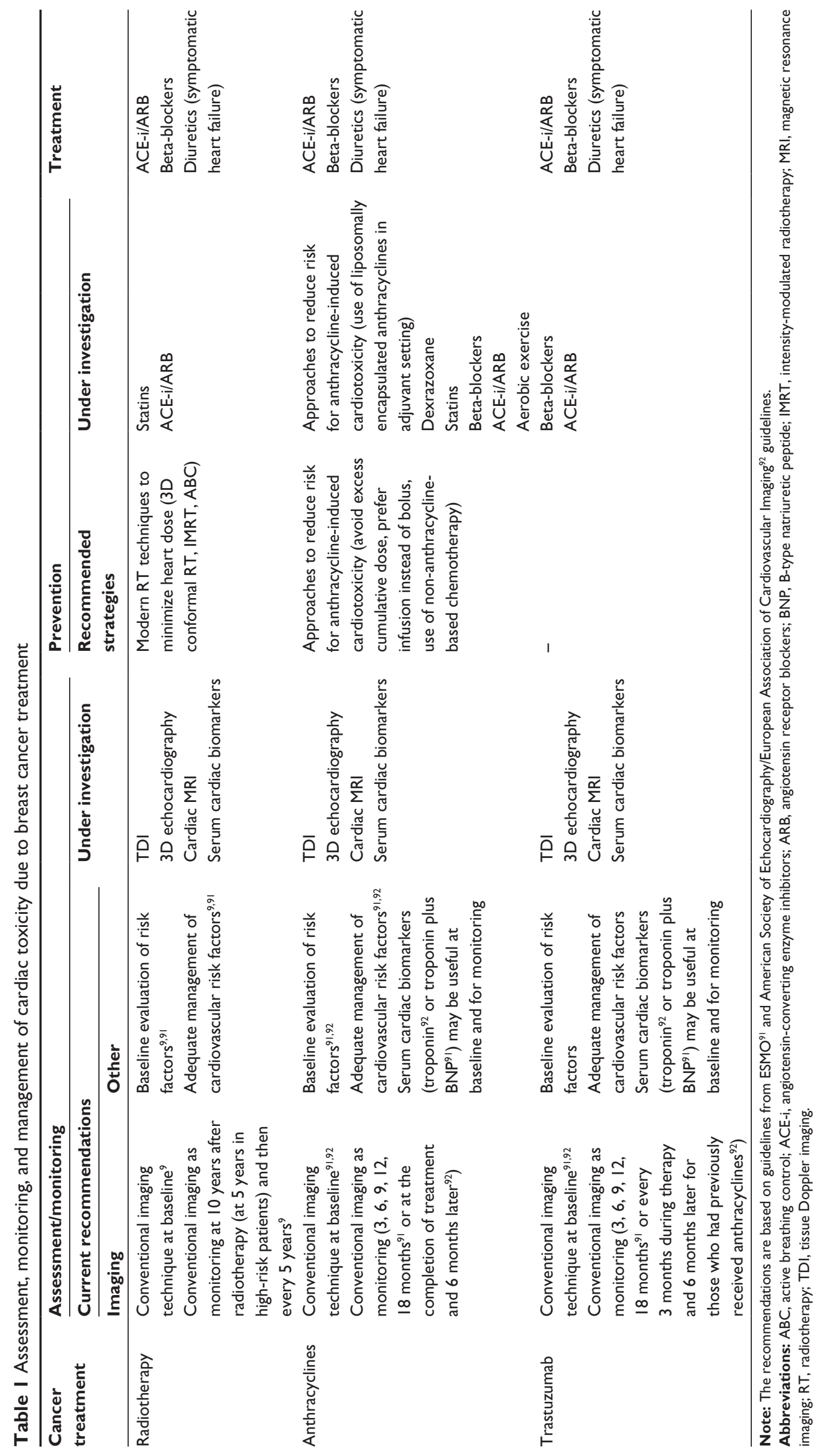


NSABP B-31 trial (trastuzumab versus no trastuzumab in the adjuvant setting) to predict the absolute risk of heart failure in individual patients who received trastuzumab as adjuvant therapy. ${ }^{96}$ However, the lack of independent validation of the model limits its clinical use so far.

The baseline evaluation also includes a cardiac imaging test for the evaluation of cardiac structure and function. ${ }^{9,91-95}$ Some guidelines recognize the practical difficulty to perform baseline imaging evaluation on all the patients with breast cancer before adjuvant treatment and recommend evaluation only for women with risk factors for cardiac toxicities or those who are planned to receive high cumulative doses of anthracyclines or at least two therapies that could influence heart function..$^{93}$ However, baseline imaging is mandatory for all the patients who are planned to receive trastuzumab without any exceptions. ${ }^{91,92}$

At present, the most frequently used modality for detecting cardiotoxicity is the measurement of LVEF by using either echocardiography or multigated acquisition scanning (MUGA). Echocardiography is generally preferred over MUGA due to its widespread availability, the ability to investigate the diastolic function as well, and the absence of radiation exposure. ${ }^{97}$ However, echocardiography is dependent on expertise and interpretation of echocardiographers while MUGA offers a more objective and reliable calculation of LVEF. $^{97}$

The major shortcoming in measuring LVEF is that it is insensitive to slight changes in myocardial function. ${ }^{98}$ As a consequence, the decrease in LVEF occurs when a critical amount of myocardial damage, which might be irreversible, has already occurred. ${ }^{99,100}$ Moreover, LVEF is a measurement of systolic cardiac function and it does not provide any assessment of other measurements such as diastolic function or valvular structure and function.

Novel ultrasound imaging techniques including tissue Doppler imaging (TDI) and 3D and contrast echocardiography could overcome some of the shortcomings of conventional echocardiography. Contrast and 3D echocardiography offer a more accurate calculation of LVEF compared with standard 2D echocardiography. ${ }^{101,102}$ In addition, 3D echocardiography might provide a tool for earlier identification of subclinical myocardial damages. ${ }^{103}$ TDI is a relatively new echocardiographic technique that uses Doppler principles to measure the velocity of myocardial motion, deformation (strain), and rate of deformation (strain rate). Clinical studies have found that TDI measurements are able to detect preclinical changes in systolic function before conventional changes in LVEF, irrespective of the cancer therapy (anthra- cyclines, radiotherapy, trastuzumab) that was responsible for the cardiac toxicity. ${ }^{104-107}$ Recently, studies on the general population found that the coronary artery score, by using computed tomography, could serve as an additional marker for the prediction of coronary artery disease. ${ }^{108}$ Whether this marker can be used in the baseline assessment of patients with breast cancer before adjuvant therapy is unknown. Further studies are necessary to identify the predictive value of these imaging modalities.

Cardiac magnetic resonance imaging is considered the gold standard for LVEF assessment and volume and mass measurements. Early studies in cancer patients allow accurate identification of subclinical or established cardiotoxicity from cancer therapy. ${ }^{109}$ However, its lack of availability and high cost limit its routine use. In a recent review, the authors concluded that based on the current data of cost and availability of the method, magnetic resonance imaging seems to be an important complement to the current algorithms of cardiac assessment and monitoring rather than a screening tool for all the patients treated with cardiotoxic cancer therapy. ${ }^{109}$

Besides imaging modalities, a new approach based on biochemical cardiac markers (troponins T and I, B-type natriuretic peptide [BNP], N-terminal pro-BNP [NT-proBNP]) has emerged as a tool for both baseline assessment and monitoring during cancer therapy. In patients treated with anthracyclines, an early elevation of troponin seems to identify patients at risk for cardiac toxicity which allows the individualization of monitoring and the adoption of preventive strategies in selected patients. ${ }^{110,111}$ Similarly, in patients treated with trastuzumab, elevation of troponin during therapy could identify a group of patients at high risk for cardiac toxicity and with a lower likelihood of recovery of cardiac function. ${ }^{12-114}$ However, others have failed to detect any clinical value of cardiac troponins during or following cancer therapy. ${ }^{107,115}$

The family of natriuretic peptides (BNP, NT-proBNP) has also been investigated as markers of early cardiac damage during cancer therapy with less reliable and consistent results than troponin. Some studies have found an association between elevation of BNP or NT-proBNP and higher risk for cardiac toxicity ${ }^{116-118}$ while others did not find any correlation at all. ${ }^{119-121}$

There are a number of barriers in cardiac biomarker studies that limit their widespread application as early markers of cancer therapy-induced cardiac toxicity. First, the timing of biomarker assessment varied among studies, which may in part explain the inconsistent results, and the optimal timing remains unanswered. Moreover, the optimal assay as well as 
a widely acceptable cut-off value is still to be determined. In addition, most of the available studies are small with heterogeneous cancer populations who received multiple types of cancer therapy. As a result, the utility of cardiac biomarkers as diagnostic and predictive tools for cardiac dysfunction in patients with potential cardiotoxic cancer therapy remains to be clarified when results from larger ongoing studies are available. Despite these caveats, some guidelines have already included the measurements of cardiac biomarkers in their suggested algorithms..$^{91,92}$

\section{Guidelines on cardiac monitoring}

The same imaging modalities and cardiac biomarkers that were discussed earlier as methods for baseline assessment and evaluation are also available as methods for cardiac monitoring during cancer therapy. Echocardiography or MUGA for the calculation of LVEF is the current backbone to all the current guidelines regarding cardiac monitoring during cancer therapy. ${ }^{9,91-95}$

The ESMO guidelines recommend serial monitoring of cardiac function with echocardiography or MUGA at baseline; at 3,6, and 9 months during treatment (anthracyclines and/or trastuzumab); and then at 12 and 18 months after the initiation of treatment. ${ }^{91}$ The authors discuss also the possibility of the use of repeated measurements of cardiac biomarkers as an additional monitoring. ${ }^{91}$ However, they recognize the need for further data by classifying this recommendation as B, with a level of evidence III. There are no recommendations about the assessment and monitoring of breast cancer patients treated with radiotherapy in the ESMO guidelines. ${ }^{91}$

The guidelines from the American Society of Echocardiography (ASE) and the European Association of Cardiovascular Imaging (EACVI) are largely similar to the ESMO guidelines concerning the time intervals in cardiac monitoring during trastuzumab therapy and the potential value of cardiac biomarkers in the baseline assessment and monitoring. ${ }^{92}$ However, there are some differences in some recommendations: the ASE/EACVI guidelines recommend cardiac monitoring 6 months after completion of trastuzumab therapy only in patients who had previously received a type I cardiotoxic agent (ie, anthracyclines); besides cardiac biomarkers, the ASE/EACVI guidelines recommend (with the same grade of recommendation) the use of an additional echocardiographic parameter, namely global longitudinal strain; and the ASE/EACVI guidelines recommend that the cardiac monitoring during anthracycline-based chemotherapy will be at baseline, at the completion, and 6 months after the completion of the treatment.
The same societies (ASE/EACVI) currently released the first guidelines about assessment and cardiac monitoring in adult patients with cancer treated with radiotherapy that will result in a radiation dose to the heart. ${ }^{9}$ The authors recommend baseline assessment of cardiovascular risk factors and baseline echocardiography to identify any cardiac abnormalities for all the patients before radiotherapy. During follow-up, a yearly history and physical examination with close attention to symptoms and signs of heart disease is recommended. In asymptomatic patients, screening echocardiography is recommended 10 years after treatment (or 5 years in case of high-risk populations, namely those who received leftside chest radiotherapy or those with at least one risk factor for RIHD) and then every 5 years after the initial 10-year echocardiographic screening examination. In the high-risk population, noninvasive stress imaging to screen for coronary artery disease should be considered due to the increased risk of coronary events 5-10 years after radiotherapy. ${ }^{9}$

\section{Prevention and management of cardiac toxicity in breast cancer survivors Strategies to prevent cardiac toxicity}

There is a growing interest in the use of standard cardiovascular medications to prevent cardiac toxicity due to cancer therapy in breast cancer patients. HMG-CoA reductase inhibitors (statins) have been shown to attenuate doxorubicininduced cardiomyocyte cell death ${ }^{122}$ and radiation-induced cell apoptosis ${ }^{123}$ in preclinical studies. One retrospective study (201 patients) ${ }^{124}$ and one small randomized trial (40 patients) ${ }^{125}$ support the potential role of statins in reducing heart failure and maintaining cardiac function in breast cancer patients treated with anthracyclines. No clinical data on the potential protective effect of statins in radiation-induced cardiac toxicity are available. Several studies that investigate the use of statins to prevent cancer therapy-associated cardiac toxicity in breast cancer patients are ongoing and the results will enlighten their role as cardioprotective agents.

Beta-blockers have also been studied as preventive agents against cardiac toxicity in breast cancer patients. Although the exact mechanism of cardioprotection with beta-blockers remains to be determined, several mechanisms have been proposed based on preclinical data including mitigation of oxidative stress ${ }^{126}$ and preservation of b-adrenergic receptor recruitment of b-arrestin, which is an endogenous protective agent. ${ }^{127}$ In the only published randomized trial dedicated to patients with breast cancer, the administration of nebivolol 
$(n=27)$ under anthracycline-based chemotherapy was associated with lower risk for LVEF decline at 6 months compared to the placebo arm $(n=18) .{ }^{128}$ Similar data were observed in two additional randomized trials: a small trial with 50 patients treated with anthracycline-based chemotherapy (34 of 50 patients had breast cancer) in which carvedilol was compared to placebo, ${ }^{129}$ and a larger trial including 90 patients with hematologic malignancies in which the combination of enalapril and carvedilol was compared to nonintervention. ${ }^{130}$ This latter trial (OVERCOME trial) is the first randomized trial investigating the protective effect of cardiovascular medication in cancer treatment-related cardiotoxicity that presented not only data on surrogate outcomes of cardiac toxicity, but also clinically relevant outcomes such as symptomatic heart failure and death. Interestingly, patients in the intervention group had a lower incidence of the combined event of death or heart failure in comparison with nonintervention group. ${ }^{130}$ In contrast with beta-blockers and anthracycline-based cardiotoxicity, there is scarce clinical evidence about the role of beta-blockers in trastuzumab-associated cardiotoxicity. Two retrospective studies have found that the combination of beta-blockers and angiotensin-converting enzyme inhibitors (ACE-i) lead to higher possibility for LVEF recovery. ${ }^{131,132}$ As we pointed out for the statins, several randomized trials are ongoing and will hopefully give a definitive answer to the question of the role of beta-blockers as cardioprotective agents in anthracyclineand trastuzumab-associated cardiac toxicity.

The third category of cardiovascular medication with potential benefit as a cardioprotective agent for cancer therapy-related cardiotoxicity is ACE-i/angiotensin II receptor blockers (ARB). Several mechanisms that could mediate this cardioprotective effect have been proposed based on preclinical data: reduction in interstitial fibrosis, ${ }^{133}$ attenuation of oxidative stress, ${ }^{134}$ and downregulation of the actions of the NRG-1/ErbB system. ${ }^{135}$ Several small randomized trials have found that the administration of ACE-i/ARB during anthracycline-based chemotherapy reduces the risk for cardiac dysfunction as it is measured by conventional cardiac imaging modalities. ${ }^{136-138}$ In addition, in the previously mentioned OVERCOME trial, the combination of beta-blockers and ACE-i resulted in lower risk for clinically relevant outcomes as well. ${ }^{130}$ The study of Cardinale et al is unique in its design since the authors used a biomarker (troponin I) to guide treatment. ${ }^{138}$ The authors used the elevation of troponin I which was measured soon after high-dose chemotherapy to select 114 patients with various malignancies for randomization to placebo versus enalapril
$20 \mathrm{mg}$ daily for 1 year. The incidence of LVEF decline $>10 \%$ was significantly higher in the control (43\%) than in the ACE-i treated arm (0\%). ${ }^{138}$ There is only preclinical data; there is no clinical evidence on the potential cardioprotective effect of ACE-i/ARB under trastuzumab or radiation therapy. ${ }^{139}$ However, this potential cardioprotective effect is an area of active investigation.

Besides the pharmacological interventions, some preclinical data suggest that even nonpharmacological interventions may have an impact in the prevention of cardiac toxicity. It has been found that aerobic exercise attenuates doxorubicininduced cardiotoxicity in animal models. ${ }^{140}$ However, a small study in patients treated with trastuzumab found that the exercise training was not effective in preventing adverse left ventricular remodeling. ${ }^{141}$ Whether the aerobic exercise is a protective intervention against anthracycline- or trastuzumabrelated cardiac toxicity in breast cancer patients needs to be studied in further randomized trials.

The only medication that has been approved by the US Food and Drug Administration for the prevention of anthracycline-related cardiotoxicity is dexrazoxane. Its mechanism of action and clinical evidence for its use was described earlier in this review. It is basically not in use in clinical practice due to concerns about the potential negative impact on antitumoral activity of anthracyclines. ${ }^{38}$

\section{Management of cardiac toxicity}

In the general population, the guidelines suggest the use of beta-blocker and ACE-i/ARB in patients with asymptomatic LVEF decline. ${ }^{142}$ It is generally accepted that a similar treatment strategy, namely the initiation of appropriate medication promptly after the detection of asymptomatic cardiac dysfunction, should be obtained in patients with cardiac dysfunction due to cancer therapy as well. ${ }^{91}$ However, the evidence behind this treatment strategy for cancer patients is coming from relatively small prospective studies ${ }^{138,143}$ and further studies, preferably randomized trials, are still needed. In trastuzumab-treated patients, the evidence that supports the use of ACE-i/ARB with or without beta-blockers in asymptomatic cardiac dysfunction (LVEF $<40 \%{ }^{92,94}$ or between $40 \%$ and $50 \%$ in some guidelines ${ }^{91}$ ) is limited to small case series, but this strategy is generally accepted..$^{91,144}$ Two additional parameters that should be taken into account in trastuzumab-induced cardiac toxicity are the need to withhold trastuzumab according to specific criteria (LVEF $\leq 44$, or LVEF $45-49$ and $\geq 10$ from baseline $)^{145}$ with reevaluation after 3-4 weeks, ${ }^{91,144}$ and the fact that the therapeutic target with cardiovascular medications should be achieved 
faster than in the general population in order to readminister trastuzumab. ${ }^{146}$

In cases of symptomatic heart failure due to cancer therapy, the recommended treatment strategy does not differ from the treatment of heart failure patients in general ${ }^{91}$ and includes routine use of ACE-i or ARB and beta-blockers with diuretics added for symptomatic congestion. In trastuzumabinduced heart failure, LVEF should be reevaluated after adequate dose titration of cardiovascular medication and, if it returns to baseline, trastuzumab can be restarted in combination with cardiovascular medications. ${ }^{91,144}$ If LVEF stays persistently low or further declines, or in case of recurrence of heart failure symptoms, the treating oncologist should discuss with the patient the risk and benefit of discontinuation of trastuzumab. ${ }^{91,144}$ Patients with radiation-induced heart diseases should be treated as non-radiation-related patients. ${ }^{91}$

\section{Conclusion}

Adjuvant treatment with radiotherapy, anthracycline-based chemotherapy, and/or trastuzumab are important parts of postoperative therapy for many women with early breast cancer. These treatment strategies are associated with cardiac adverse events through different pathophysiological mechanisms. Several guidelines recommend initial baseline assessment and appropriate cardiac monitoring to reveal cardiac dysfunction at an early stage of cancer therapy. However, several important issues remain unresolved including the optimal timing of assessment; monitoring and initiation of cardiovascular medication; the role of modern imaging modalities as well as the role of cardiac biomarkers as early predictors of cardiac toxicity; the potential role of cardiovascular medications as cardioprotective agents; and the value of new radiotherapy techniques in reducing long-term cardiotoxicity. These issues are the focus of ongoing research. An extensive collaboration between cardiologists and oncologists in the fields of both scientific research and clinical practice is essential to further develop and implement adequate cardioprotective strategies for patients with early breast cancer.

\section{Disclosure}

The authors report no conflict of interest in this work.

\section{References}

1. GLOBOCAN 2012: Estimated Cancer Incidence, Mortality and Prevalence Worldwide in 2012 [webpage on the Internet]. Lyon: International Agency for Research on Cancer; 2012. Available from: http://globocan.iarc.fr/Pages/fact_sheets_cancer.aspx. Accessed October 10, 2014.
2. Siegel R, Naishadham D, Jemal A. Cancer statistics, 2012. CA Cancer J Clin. 2012;62(1):10-29.

3. Early Breast Cancer Trialists' Collaborative Group (EBCTCG), Darby S, McGale $\mathrm{P}$, et al. Effect of radiotherapy after breast-conserving surgery on 10-year recurrence and 15-year breast cancer death: meta-analysis of individual patient data for 10,801 women in 17 randomised trials. Lancet. 2011;378(9804):1707-1716.

4. Recht A, Edge SB, Solin LJ, et al. Postmastectomy radiotherapy: clinical practice guidelines of the American Society of Clinical Oncology. J Clin Oncol. 2001;19(5):1539-1569.

5. EBCTCG (Early Breast Cancer Trialists' Collaborative Group), McGale P, Taylor C. Effect of radiotherapy after mastectomy and axillary surgery on 10 -year recurrence and 20 -year breast cancer mortality: meta-analysis of individual patient data for 8135 women in 22 randomised trials. Lancet. 2014;383(9935):2127-2135.

6. Clarke M, Collins R, Darby S, et al. Effects of radiotherapy and of differences in the extent of surgery for early breast cancer on local recurrence and 15-year survival: an overview of the randomised trials. Lancet. 2005;366(9503):2087-2106.

7. Hooning MJ, Botma A, Aleman BM, et al. Long-term risk of cardiovascular disease in 10-year survivors of breast cancer. $J$ Natl Cancer Inst. 2007;99(5):365-375.

8. Bouillon K, Haddy N, Delaloge S, et al. Long-term cardiovascular mortality after radiotherapy for breast cancer. $\mathrm{J} \mathrm{Am} \mathrm{Coll} \mathrm{Cardiol.}$ 2011;57(4):445-452.

9. Lancellotti P, Nkomo VT, Badano LP, et al. Expert consensus for multimodality imaging evaluation of cardiovascular complications of radiotherapy in adults: a report from the European Association of Cardiovascular Imaging and the American Society of Echocardiography. Eur Heart J Cardiovasc Imaging. 2013;14(8): 721-740.

10. Roychoudhuri R, Robinson D, Putcha V, Cuzick J, Darby S, Møller H. Increased cardiovascular mortality more than fifteen years after radiotherapy for breast cancer: a population-based study. BMC Cancer. 2007;7:9.

11. Darby SC, McGale P, Taylor CW, Peto R. Long-term mortality from heart disease and lung cancer after radiotherapy for early breast cancer: prospective cohort study of about 300,000 women in US SEER cancer registries. Lancet Oncol. 2005;6(8):557-565.

12. Harris EE, Correa C, Hwang WT, et al. Late cardiac mortality and morbidity in early-stage breast cancer patients after breast-conservation treatment. J Clin Oncol. 2006;24(25):4100-4106.

13. Darby SC, Ewertz M, McGale P, et al. Risk of ischemic heart disease in women after radiotherapy for breast cancer. $N$ Engl $J$ Med. 2013;368(11):987-998.

14. Taylor CW, Nisbet A, McGale P, Darby SC. Cardiac exposures in breast cancer radiotherapy: 1950s-1990s. Int J Radiat Oncol Biol Phys. 2007;69(5):1484-1495.

15. Taylor CW, Povall JM, McGale P, et al. Cardiac dose from tangential breast cancer radiotherapy in the year 2006. Int J Radiat Oncol Biol Phys. 2008;72(2):501-507.

16. Nilsson G, Holmberg L, Garmo H, et al. Distribution of coronary artery stenosis after radiation for breast cancer. J Clin Oncol. 2012;30(4):380-386.

17. Correa CR, Litt HI, Hwang WT, Ferrari VA, Solin LJ, Harris EE. Coronary artery findings after left-sided compared with right-sided radiation treatment for early-stage breast cancer. J Clin Oncol. 2007;25(21):3031-3037.

18. http://www.dbcg.dk [homepage on the Internet]. Copenhagen: Danish Breast Cancer Cooperative Group. Available from: http://www.dbcg.dk. Accessed October 10, 2014.

19. Bartlett FR, Yarnold JR, Donovan EM, Evans PM, Locke I, Kirby AM. Multileaf collimation cardiac shielding in breast radiotherapy: Cardiac doses are reduced, but at what cost? Clin Oncol (R Coll Radiol). 2013;25(12):690-696.

20. Poortmans PSH, Kirkove C, Budach V, et al. Irradiation of the internal mammary and medial supraclavicular lymph nodes in stage I to III breast cancer: 10 years results of the EORTC radiation oncology and breast cancer groups phase III trial 22922/10925. Eur J Cancer. 2013;47(Suppl 2). 
21. Whelan TJ, Olivotto I, Ackerman I, et al. NCIC-CTG MA.20: an intergroup trial of regional nodal irradiation in early breast cancer. $J$ Clin Oncol. 2011;29:LBA1003.

22. Hennequin C, Bossard N, Servagi-Vernat S, et al. Ten-year survival results of a randomized trial of irradiation of internal mammary nodes after mastectomy. Int J Radiat Oncol Biol Phys. 2013;86(5): 860-866.

23. Mast ME, van Kempen-Harteveld L, Heijenbrok MW, et al. Leftsided breast cancer radiotherapy with and without breath-hold: does IMRT reduce the cardiac dose even further? Radiother Oncol. 2013;108(2):248-253

24. Zellars R, Bravo PE, Tryggestad E, et al. SPECT analysis of cardiac perfusion changes after whole-breast/chest wall radiation therapy with or without active breathing coordinator: results of a randomized phase 3 trial. Int J Radiat Oncol Biol Phys. 2014;88(4):778-785.

25. Osman SO, Hol S, Poortmans PM, Essers M. Volumetric modulated arc therapy and breath-hold in image-guided locoregional left-sided breast irradiation. Radiother Oncol. 2014;112(1):17-22.

26. Mast ME, Vredeveld EJ, Credoe HM, et al. Whole breast proton irradiation for maximal reduction of heart dose in breast cancer patients. Breast Cancer Res Treat. 2014;148(1):33-39.

27. Prescott RJ, Kunkler IH, Williams LJ, et al. A randomised controlled trial of postoperative radiotherapy following breast-conserving surgery in a minimum-risk older population. The PRIME trial. Health Technol Assess. 2007;11(31):1-149.

28. Kaklamani VG, Gradishar WJ. Epirubicin versus doxorubicin: which is the anthracycline of choice for the treatment of breast cancer? Clin Breast Cancer. 2003;4 Suppl 1:S26-S33.

29. Singal PK, Iliskovic N. Doxorubicin-induced cardiomyopathy. $N$ Engl J Med. 1998;339:900-905.

30. Lyu YL, Kerrigan JE, Lin CP, et al. Topoisomerase IIbeta mediated DNA double-strand breaks: implications in doxorubicin cardiotoxicity and prevention by dexrazoxane. Cancer Res. 2007;67: 8839-8846.

31. Ewer MS, Lippman SM. Type II chemotherapy-related cardiac dysfunction: time to recognize a new entity. J Clin Oncol. 2005;23: 2900-2902.

32. Smith LA, Cornelius VR, Plummer CJ, et al. Cardiotoxicity of anthracycline agents for the treatment of cancer: systematic review and meta-analysis of randomised controlled trials. BMC Cancer. 2010;10:337.

33. Lotrionte $\mathrm{M}$, Biondi-Zoccai G, Abbate A, et al. Review and meta-analysis of incidence and clinical predictors of anthracycline cardiotoxicity. Am J Cardiol. 2013;112(12):1980-1984.

34. Swain SM, Whaley FS, Ewer MS. Congestive heart failure in patients treated with doxorubicin: a retrospective analysis of three trials. Cancer. 2003;97:2869-2879.

35. Ryberg M, Nielsen D, Skovsgaard T, Hansen J, Jensen BV, Dombernowsky P. Epirubicin cardiotoxicity: an analysis of 469 patients with metastatic breast cancer. J Clin Oncol. 1998;16:3502-3508.

36. Minotti G, Licata S, Saponiero A, et al. Anthracycline metabolism and toxicity in human myocardium: comparisons between doxorubicin, epirubicin, and a novel disaccharide analogue with a reduced level of formation and [4Fe-4S] reactivity of its secondary alcohol metabolite. Chem Res Toxicol. 2000;13:1336-1341.

37. Ryberg M, Nielsen D, Cortese G, Nielsen G, Skovsgaard T, Andersen PK. New insight into epirubicin cardiac toxicity: competing risks analysis of 1097 breast cancer patients. J Natl Cancer Inst. 2008;100:1058-1067.

38. van Dalen EC, van der Pal HJ, Caron HN, Kremer LC. Different dosage schedules for reducing cardiotoxicity in cancer patients receiving anthracycline chemotherapy. Cochrane Database Syst Rev. 2006;4:CD005008.

39. Giotta F, Lorusso V, Maiello E, et al. Liposomal-encapsulated doxorubicin plus cyclophosphamide as first-line therapy in metastatic breast cancer: a phase II multicentric study. Ann Oncol. 2007;18 Suppl 6: vi66-vi69.
40. Brain EG, Mertens C, Girre V, et al. Impact of liposomal doxorubicinbased adjuvant chemotherapy on autonomy in women over 70 with hormone-receptor-negative breast carcinoma: A French Geriatric Oncology Group (GERICO) phase II multicentre trial. Crit Rev Oncol Hematol. 2011;80(1):160-170.

41. Rayson D, Suter TM, Jackisch C, et al. Cardiac safety of adjuvant pegylated liposomal doxorubicin with concurrent trastuzumab: a randomized phase II trial. Ann Oncol. 2012;23(7):1780-1788.

42. Joo KI, Xiao L, Liu S, et al. Crosslinked multilamellar liposomes for controlled delivery of anticancer drugs. Biomaterials. 2013;34(12):3098-3109.

43. Liu Y, Fang J, Kim YJ, Wong MK, Wang P. Codelivery of doxorubicin and paclitaxel by cross-linked multilamellar liposome enables synergistic antitumor activity. Mol Pharm. 2014;11(5):1651-1661.

44. Slamon D, Eiermann W, Robert N, et al. Adjuvant trastuzumab in HER2positive breast cancer. $N$ Engl J Med. 2011;365(14):1273-1283.

45. Early Breast Cancer Trialists' Collaborative Group (EBCTCG), Peto R, Davies C. Comparisons between different polychemotherapy regimens for early breast cancer: meta-analyses of long-term outcome among 100,000 women in 123 randomised trials. Lancet. 2012;379(9814):432-444.

46. Rowinsky EK, McGuire WP, Guarnieri T, Fisherman JS, Christian MC, Donehower RC. Cardiac disturbances during the administration of taxol. J Clin Oncol. 1991;9:1704-1712.

47. Shimoyama M, Murata Y, Sumi KI, Hamazoe R, Komuro I. Docetaxel induced cardiotoxicity. Heart. 2001;86(2):219.

48. Arbuck SG, Strauss H, Rowinsky E, et al. A reassessment of cardiac toxicity associated with Taxol. J Natl Cancer Inst Monogr. 1993;(15):117-130.

49. Gianni L, Salvatorelli E, Minotti G. Anthracycline cardiotoxicity in breast cancer patients: synergism with trastuzumab and taxanes. Cardiovasc Toxicol. 2007;7:67-71.

50. Giordano SH, Booser DJ, Murray JL, et al. A detailed evaluation of cardiac toxicity: a phase II study of doxorubicin and one- or threehour-infusion paclitaxel in patients with metastatic breast cancer. Clin Cancer Res. 2002;8:3360-3368.

51. Gennari A, Salvadori B, Donati S, et al. Cardiotoxicity of epirubicin/ paclitaxel-containing regimens: role of cardiac risk factors. $J$ Clin Oncol. 1999;17:3596-3602.

52. Petrelli F, Borgonovo K, Cabiddu M, Lonati V, Barni S. Mortality, leukemic risk, and cardiovascular toxicity of adjuvant anthracycline and taxane chemotherapy in breast cancer: a meta-analysis. Breast Cancer Res Treat. 2012;135(2):335-346.

53. Early Breast Cancer Trialists' Collaborative Group (EBCTCG). Effects of chemotherapy and hormonal therapy for early breast cancer on recurrence and 15-year survival: an overview of the randomised trials. Lancet. 2005;365(9472):1687-1717.

54. Breast International Group (BIG) 1-98 Collaborative Group, Thürlimann B, Keshaviah A. A comparison of letrozole and tamoxifen in postmenopausal women with early breast cancer. $N$ Engl $J$ Med. 2005;353(26):2747-2757

55. Coombes RC, Kilburn LS, Snowdon CF, et al. Survival and safety of exemestane versus tamoxifen after 2-3 years' tamoxifen treatment (Intergroup Exemestane Study): a randomised controlled trial. Lancet. 2007;369(9561):559-570.

56. Howell A, Cuzick J, Baum M, et al. Results of the ATAC (Arimidex, Tamoxifen, Alone or in Combination) trial after completion of 5 years' adjuvant treatment for breast cancer. Lancet. 2005; 365(9453):60-62.

57. Smith IE, Dowsett M. Aromatase inhibitors in breast cancer. $N$ Engl $J$ Med. 2003;348(24):2431-2442.

58. Lin C, Chen LS, Kuo SJ, Chen DR. Adjuvant tamoxifen influences the lipid profile in breast cancer patients. Breast Care (Basel). 2014;9(1):35-39.

59. Braithwaite RS, Chlebowski RT, Lau J, George S, Hess R, Col NF. Meta-analysis of vascular and neoplastic events associated with tamoxifen. J Gen Intern Med. 2003;18(11):937-947. 
60. Arimidex, Tamoxifen, Alone or in Combination Trialists' Group, Buzdar A, Howell A. Comprehensive side-effect profile of anastrozole and tamoxifen as adjuvant treatment for early-stage breast cancer: long-term safety analysis of the ATAC trial. Lancet Oncol. 2006;7(8):633-646.

61. Mouridsen H, Keshaviah A, Coates AS, et al. Cardiovascular adverse events during adjuvant endocrine therapy for early breast cancer using letrozole or tamoxifen: safety analysis of BIG 1-98 trial. J Clin Oncol. 2007;25(36):5715-5722.

62. Bliss JM, Kilburn LS, Coleman RE, et al. Disease-related outcomes with long-term follow-up: an updated analysis of the intergroup exemestane study. J Clin Oncol. 2012;30(7):709-717.

63. Goss PE, Ingle JN, Martino S, et al. Randomized trial of letrozole following tamoxifen as extended adjuvant therapy in receptor-positive breast cancer: updated findings from NCIC CTG MA.17. J Natl Cancer Inst. 2005;97(17):1262-1271.

64. Dawood S, Broglio K, Buzdar AU, Hortobagyi GN, Giordano SH. Prognosis of women with metastatic breast cancer by HER2 status and trastuzumab treatment: an institutional-based review. J Clin Oncol. 2010;28(1):92-98.

65. Viani GA, Afonso SL, Stefano EJ, De Fendi LI, Soares FV. Adjuvant trastuzumab in the treatment of her-2-positive early breast cancer: a metaanalysis of published randomized trials. BMC Cancer. 2007;7:153.

66. Seidman A, Hudis C, Pierri MK, et al. Cardiac dysfunction in the trastuzumab clinical trials experience. J Clin Oncol. 2002;20(5): 1215-1221.

67. Onitilo AA, Engel JM, Stankowski RV. Cardiovascular toxicity associated with adjuvant trastuzumab therapy: prevalence, patient characteristics, and risk factors. Ther Adv Drug Saf. 2014;5(4):154-166.

68. Moja L, Tagliabue L, Balduzzi S, et al. Trastuzumab containing regimens for early breast cancer. Cochrane Database Syst Rev. 2012;4:CD006243.

69. Bowles EJ, Wellman R, Feigelson HS, et al. Risk of heart failure in breast cancer patients after anthracycline and trastuzumab treatment a retrospective cohort study. J Natl Cancer Inst. 2012;104(17) 1293-1305.

70. Naumann D, Rusius V, Margiotta C, et al. Factors predicting trastuzumabrelated cardiotoxicity in a real-world population of women with HER2+ breast cancer. Anticancer Res. 2013;33(4):1717-1720.

71. Zhao YY, Sawyer DR, Baliga RR, et al. Neuregulins promote survival and growth of cardiac myocytes. Persistence of ErbB2 and ErbB4 expression in neonatal and adult ventricular myocytes. $J$ Biol Chem. 1998;273(17):10261-10269.

72. De Keulenaer GW, Doggen K, Lemmens K. The vulnerability of the heart as a pluricellular paracrine organ: Lessons from unexpected triggers of heart failure in targeted erbb2 anticancer therapy. Circ Res. 2010;106(1):35-46.

73. Farolfi A, Melegari E, Aquilina M, et al. Trastuzumab-induced cardiotoxicity in early breast cancer patients: a retrospective study of possible risk and protective factors. Heart. 2013;99(9):634-639.

74. Russo G, Cioffi G, Di Lenarda A, et al. Role of renal function on the development of cardiotoxicity associated with trastuzumab-based adjuvant chemotherapy for early breast cancer. Intern Emerg Med. 2012;7(5):439-446.

75. Cochet A, Quilichini G, Dygai-Cochet I, et al. Baseline diastolic dysfunction as a predictive factor of trastuzumab-mediated cardiotoxicity after adjuvant anthracycline therapy in breast cancer. Breast Cancer Res Treat. 2011;130(3):845-854.

76. Valachis A, Mauri D, Polyzos NP, Chlouverakis G, Mavroudis D, Georgoulias V. Trastuzumab combined to neoadjuvant chemotherapy in patients with HER2-positive breast cancer: a systematic review and meta-analysis. Breast. 2011;20(6):485-490.

77. Schneeweiss A, Chia S, Hickish T, et al. Pertuzumab plus trastuzumab in combination with standard neoadjuvant anthracycline-containing and anthracycline-free chemotherapy regimens in patients with HER2positive early breast cancer: a randomized phase II cardiac safety study (TRYPHAENA). Ann Oncol. 2013;24(9):2278-2284.
78. Buzdar AU, Suman VJ, Meric-Bernstam F, et al. Fluorouracil, epirubicin, and cyclophosphamide (FEC-75) followed by paclitaxel plus trastuzumab versus paclitaxel plus trastuzumab followed by FEC-75 plus trastuzumab as neoadjuvant treatment for patients with HER2positive breast cancer (Z1041): a randomised, controlled, phase 3 trial. Lancet Oncol. 2013;14(13):1317-1325.

79. Perez EA, Suman VJ, Davidson NE, et al. Cardiac safety analysis of doxorubicin and cyclophosphamide followed by paclitaxel with or without trastuzumab in the North Central Cancer Treatment Group N9831 adjuvant breast cancer trial. J Clin Oncol. 2008;26(8):1231-1238.

80. Chen J, Long JB, Hurria A, Owusu C, Steingart RM, Gross CP. Incidence of heart failure or cardiomyopathy after adjuvant trastuzumab therapy for breast cancer. $J$ Am Coll Cardiol. 2012;60(24):2504-2512.

81. Serrano C, Cortés J, De Mattos-Arruda L, et al. Trastuzumab-related cardiotoxicity in the elderly: a role for cardiovascular risk factors. Ann Oncol. 2012;23(4):897-902.

82. Beauclair S, Formento P, Fischel JL, et al. Role of the HER2 [Ile655Val] genetic polymorphism in tumorogenesis and in the risk of trastuzumabrelated cardiotoxicity. Ann Oncol. 2007;18(8):1335-1341.

83. Lemieux J, Diorio C, Côté MA, et al. Alcohol and HER2 polymorphisms as risk factor for cardiotoxicity in breast cancer treated with trastuzumab. Anticancer Res. 2013;33(6):2569-2576.

84. Roca L, Diéras V, Roché H, et al. Correlation of HER2, FCGR2A, and FCGR3A gene polymorphisms with trastuzumab related cardiac toxicity and efficacy in a subgroup of patients from UNICANCER-PACS 04 trial. Breast Cancer Res Treat. 2013;139(3):789-800.

85. Geyer CE, Forster J, Lindquist D, et al. Lapatinib plus capecitabine for HER2-positive advanced breast cancer. $N$ Engl $J$ Med. 2006;355:2733-2743.

86. Baselga J, Cortés J, Kim SB, et al. Pertuzumab plus trastuzumab plus docetaxel for metastatic breast cancer. $N$ Engl J Med. 2012;366: 109-119.

87. Gianni L, Pienkowski T, Im YH, et al. Efficacy and safety of neoadjuvant pertuzumab and trastuzumab in women with locally advanced, inflammatory, or early HER2-positive breast cancer (NeoSphere): a randomised multicentre, open-label, phase 2 trial. Lancet Oncol. 2012;13(1):25-32.

88. Valachis A, Nearchou A, Lind P, Mauri D. Lapatinib, trastuzumab or the combination added to preoperative chemotherapy for breast cancer: a meta-analysis of randomized evidence. Breast Cancer Res Treat. 2012;135(3):655-662.

89. Blackwell KL, Burstein HJ, Storniolo AM, et al. Overall survival benefit with lapatinib in combination with trastuzumab for patients with human epidermal growth factor receptor 2-positive metastatic breast cancer: final results from the EGF104900 Study. J Clin Oncol. 2012;30(21):2585-2592.

90. Valachis A, Nearchou A, Polyzos NP, Lind P. Cardiac toxicity in breast cancer patients treated with dual HER2 blockade. Int $J$ Cancer. 2013;133(9):2245-2252.

91. Curigliano G, Cardinale D, Suter T, et al. Cardiovascular toxicity induced by chemotherapy, targeted agents and radiotherapy: ESMO Clinical Practice Guidelines. Ann Oncol. 2012;23 Suppl 7: vii155-vii166.

92. Plana JC, Galderisi M, Barac A, et al. Expert consensus for multimodality imaging evaluation of adult patients during and after cancer therapy: a report from the American Society of Echocardiography and the European Association of Cardiovascular Imaging. Eur Heart $J$ Cardiovasc Imaging. 2014;15(10):1063-1093.

93. Floyd J, Morgan JP. Cardiotoxicity of anthracycline-like chemotherapy agents. In: UpToDate, Savarese DFM (Ed), UpToDate, Waltham, MA. Accessed on September 8, 2014.

94. Perez EA, Morgan JP. Cardiotoxicity of trastuzumab and other HER2targeted agents. In: UpToDate, Savarese DFM (Ed), UpToDate, Waltham, MA. (Accessed on September 15, 2014).

95. Marks LB, Constine LS, Jacob Adams M. Cardiotoxicity of radiation therapy for malignancy. In: UpToDate, Ross ME (Ed), UpToDate, Waltham, MA. (Accessed on September 1, 2014). 
96. Romond EH, Jeong JH, Rastogi P, et al. Seven-year follow-up assessment of cardiac function in NSABP B-31, a randomized trial comparing doxorubicin and cyclophosphamide followed by paclitaxel (ACP) with ACP plus trastuzumab as adjuvant therapy for patients with node-positive, human epidermal growth factor receptor 2-positive breast cancer. J Clin Oncol. 2012;30(31):3792-3799.

97. Altena R, Perik PJ, van Veldhuisen DJ, de Vries EG, Gietema JA. Cardiovascular toxicity caused by cancer treatment: strategies for early detection. Lancet Oncol. 2009;10(4):391-399.

98. Ewer MS, Ali MK, Mackay B, et al. A comparison of cardiac biopsy grades and ejection fraction estimations in patients receiving Adriamycin. J Clin Oncol. 1984;2(2):112-117.

99. Jensen BV, Skovsgaard T, Nielsen SL. Functional monitoring of anthracycline cardiotoxicity: a prospective, blinded, long-term observational study of outcome in 120 patients. Ann Oncol. 2002;13(5):699-709.

100. Ewer MS, Lenihan DJ. Left ventricular ejection fraction and cardiotoxicity: is our ear really to the ground? J Clin Oncol. 2008;26(8):1201-1203.

101. Thavendiranathan P, Grant AD, Negishi T, Plana JC, Popović ZB, Marwick TH. Reproducibility of echocardiographic techniques for sequential assessment of left ventricular ejection fraction and volumes: application to patients undergoing cancer chemotherapy. J Am Coll Cardiol. 2013;61(1):77-84.

102. Lang RM, Mor-Avi V, Dent JM, Kramer CM. Three-dimensional echocardiography: is it ready for everyday clinical use? JACC Cardiovasc Imaging. 2009;2(1):114-117.

103. Lorenzini C, Corsi C, Aquilina M, et al. Early detection of cardiotoxicity in chemotherapy-treated patients from real-time $3 \mathrm{D}$ echocardiography. Computing in Cardiology Conference (CinC). 2013:249-252.

104. Jurcut R, Wildiers H, Ganame J, et al. Strain rate imaging detects early cardiac effects of pegylated liposomal doxorubicin as adjuvant therapy in elderly patients with breast cancer. JAm Soc Echocardiogr. 2008;21(12):1283-1289.

105. Hare JL, Brown JK, Leano R, Jenkins C, Woodward N, Marwick TH. Use of myocardial deformation imaging to detect preclinical myocardial dysfunction before conventional measures in patients undergoing breast cancer treatment with trastuzumab. Am Heart J. 2009;158(2):294-301.

106. Fallah-Rad N, Walker JR, Wassef A, et al. The utility of cardiac biomarkers, tissue velocity and strain imaging, and cardiac magnetic resonance imaging in predicting early left ventricular dysfunction in patients with human epidermal growth factor receptor II-positive breast cancer treated with adjuvant trastuzumab therapy. J Am Coll Cardiol. 2011;57(22):2263-2270.

107. Erven K, Jurcut R, Weltens C, et al. Acute radiation effects on cardiac function detected by strain rate imaging in breast cancer patients. Int J Radiat Oncol Biol Phys. 2011;79(5):1444-1451.

108. Kavousi M, Elias-Smale S, Rutten JH, et al. Evaluation of newer risk markers for coronary heart disease risk classification: a cohort study. Ann Intern Med. 2012;156(6):438-444.

109. Thavendiranathan P, Wintersperger BJ, Flamm SD, Marwick TH. Cardiac MRI in the assessment of cardiac injury and toxicity from cancer chemotherapy: a systematic review. Circ Cardiovasc Imaging. 2013;6(6):1080-1091.

110. Cardinale D, Sandri MT, Colombo A, et al. Prognostic value of troponin I in cardiac risk stratification of cancer patients undergoing high-dose chemotherapy. Circulation. 2004;109(22):2749-2754.

111. Sawaya H, Sebag IA, Plana JC, et al. Early detection and prediction of cardiotoxicity in chemotherapy-treated patients. Am J Cardiol. 2011;107(9):1375-1380.

112. Cardinale D, Colombo A, Torrisi R, et al. Trastuzumab-induced cardiotoxicity: clinical and prognostic implications of troponin I evaluation. J Clin Oncol. 2010;28(25):3910-3916.

113. Sawaya H, Sebag IA, Plana JC, et al. Assessment of echocardiography and biomarkers for the extended prediction of cardiotoxicity in patients treated with anthracyclines, taxanes, and trastuzumab. Circ Cardiovasc Imaging. 2012;5(5):596-603.
114. Kutteh LA, Hobday T, Jaffe A, et al. A correlative study of cardiac biomarkers and left ventricular ejection fraction (LVEF) from N9831, a phase III randomized trial of chemotherapy and trastuzumab as adjuvant therapy for HER2-positive breast cancer. $J$ Clin Oncol. 2007;25(18S):579.

115. Raderer M, Kornek G, Weinländer G, Kastner J. Serum troponin T levels in adults undergoing anthracycline therapy. J Natl Cancer Inst. 1997;89(2):171.

116. Lenihan DJ, Massey MR, Baysinger KB, et al. Superior Detection of Cardiotoxicity during Chemotherapy Using Biomarkers. J Card Fail. 2007;13:S151.

117. Romano S, Fratini S, Ricevuto E, et al. Serial measurements of NTproBNP are predictive of not-high-dose anthracycline cardiotoxicity in breast cancer patients. Br J Cancer. 2011;105(11):1663-1668.

118. Skovgaard D, Hasbak P, Kjaer A. BNP predicts chemotherapy-related cardiotoxicity and death: comparison with gated equilibrium radionuclide ventriculography. PLoS One. 2014;9(5):e96736.

119. Dodos F, Halbsguth T, Erdmann E, Hoppe UC. Usefulness of myocardial performance index and biochemical markers for early detection of anthracycline-induced cardiotoxicity in adults. Clin Res Cardiol. 2008;97(5):318-326.

120. Knobloch K, Tepe J, Lichtinghagen R, Luck HJ, Vogt PM. Monitoring of cardiotoxicity during immunotherapy with Herceptin using simultaneous continuous wave Doppler depending on N-terminal pro-brain natriuretic peptide. Clin Med. 2007;7(1):88-89.

121. Knobloch K, Tepe J, Rossner D, et al. Combined NT-pro-BNP and $\mathrm{CW}$-Doppler ultrasound cardiac output monitoring (USCOM) in epirubicin and liposomal doxorubicin therapy. Int J Cardiol. 2008;128(3):316-325

122. Damrot J, Nubel T, Epe B, Roos WP, Kaina B, Fritz G. Lovastatin protects human endothelial cells from the genotoxic and cytotoxic effects of the anticancer drugs doxorubicin and etoposide. Br J Pharmacol. 2006;149(8):988-997.

123. Ran XZ, Ran X, Zong ZW, et al. Protective effect of atorvastatin on radiation-induced vascular endothelial cell injury in vitro. $J$ Radiat Res. 2010;51(5):527-533.

124. Seicean S, Seicean A, Plana JC, Budd GT, Marwick TH. Effect of statin therapy on the risk for incident heart failure in patients with breast cancer receiving anthracycline chemotherapy: an observational clinical cohort study. J Am Coll Cardiol. 2012;60(23): 2384-2390.

125. Acar Z, Kale A, Turgut M, et al. Efficiency of atorvastatin in the protection of anthracycline-induced cardiomyopathy. J Am Coll Cardiol. 2011;58(9):988-989.

126. Asanuma H, Minamino T, Sanada S, et al. Beta-adrenoceptor blocker carvedilol provides cardioprotection via an adenosinedependent mechanism in ischemic canine hearts. Circulation. 2004;109(22):2773-2779.

127. Kim IM, Tilley DG, Chen J, et al. Beta-blockers alprenolol and carvedilol stimulate beta-arrestin-mediated EGFR transactivation. Proc Natl Acad Sci US A. 2008;105(38):14555-14560.

128. Kaya MG, Ozkan M, Gunebakmaz O, et al. Protective effects of nebivolol against anthracycline-induced cardiomyopathy: a randomized control study. Int J Cardiol. 2013;167(5):2306-2310.

129. Kalay N, Basar E, Ozdogru I, et al. Protective effects of carvedilol against anthracycline-induced cardiomyopathy. J Am Coll Cardiol. 2006;48(11):2258-2262.

130. Bosch X, Rovira M, Sitges M, et al. Enalapril and carvedilol for preventing chemotherapy-induced left ventricular systolic dysfunction in patients with malignant hemopathies: the OVERCOME trial (preventiOn of left Ventricular dysfunction with Enalapril and caRvedilol in patients submitted to intensive ChemOtherapy for the treatment of Malignant hEmopathies). J Am Coll Cardiol. 2013;61(23):2355-2362.

131. Ewer MS, Vooletich MT, Durand JB, et al. Reversibility of trastuzumab-related cardiotoxicity: new insights based on clinical course and response to medical treatment. J Clin Oncol. 2005; 23(31):7820-7826. 
132. Oliva S, Cioffi G, Frattini S, et al; Italian Cardio-Oncological Network. Administration of angiotensin-converting enzyme inhibitors and $\beta$-blockers during adjuvant trastuzumab chemotherapy for nonmetastatic breast cancer: marker of risk or cardioprotection in the real world? Oncologist. 2012;17(7):917-924.

133. Tokudome T, Mizushige K, Noma T, et al. Prevention of doxorubicin (adriamycin)-induced cardiomyopathy by simultaneous administration of angiotensin-converting enzyme inhibitor assessed by acoustic densitometry. J Cardiovasc Pharmacol. 2000;36(3):361-368.

134. Abd El-Aziz MA, Othman AI, Amer M, El-Missiry MA. Potential protective role of angiotensin-converting enzyme inhibitors captopril and enalapril against adriamycin-induced acute cardiac and hepatic toxicity in rats. J Appl Toxicol. 2001;21(6):469-473.

135. Lemmens K, Segers VF, Demolder M, De Keulenaer GW. Role of neuregulin-1/ErbB2 signaling in endothelium-cardiomyocyte crosstalk. J Biol Chem. 2006;281(28):19469-19477.

136. Nakamae H, Tsumura K, Terada Y, et al. Notable effects of angiotensin II receptor blocker, valsartan, on acute cardiotoxic changes after standard chemotherapy with cyclophosphamide, doxorubicin, vincristine, and prednisolone. Cancer. 2005;104(11):2492-2498.

137. Dessì M, Madeddu C, Piras A, et al. Long-term, up to 18 months, protective effects of the angiotensin II receptor blocker telmisartan on Epirubin-induced inflammation and oxidative stress assessed by serial strain rate. Springerplus. 2013;2(1):198.

138. Cardinale D, Colombo A, Sandri MT, et al. Prevention of high-dose chemotherapy-induced cardiotoxicity in high-risk patients by angiotensin-converting enzyme inhibition. Circulation. 2006;114(23):2474-2481.

139. Tofield A. ACE inhibitor reduces radiation injury to myocardium. Eur Heart J. 2013;34(27):2023-2024.
140. Scott JM, Khakoo A, Mackey JR, Haykowsky MJ, Douglas PS, Jones LW. Modulation of anthracycline-induced cardiotoxicity by aerobic exercise in breast cancer: current evidence and underlying mechanisms. Circulation. 2011;124(5):642-650.

141. Haykowsky MJ, Mackey JR, Thompson RB, Jones LW, Paterson DI. Adjuvant trastuzumab induces ventricular remodeling despite aerobic exercise training. Clin Cancer Res. 2009;15(15):4963-4967.

142. Hunt SA, Abraham WT, Chin MH, et al. 2009 Focused update incorporated into the ACC/AHA 2005 Guidelines for the Diagnosis and Management of Heart Failure in Adults A Report of the American College of Cardiology Foundation/American Heart Association Task Force on Practice Guidelines Developed in Collaboration With the International Society for Heart and Lung Transplantation. J Am Coll Cardiol. 2009;53(15):e1-e90.

143. Cardinale D, Colombo A, Lamantia G, et al. Anthracycline-induced cardiomyopathy: clinical relevance and response to pharmacologic therapy. J Am Coll Cardiol. 2010;55(3):213-220.

144. Tocchetti CG, Ragone G, Coppola C, et al. Detection, monitoring, and management of trastuzumab-induced left ventricular dysfunction: an actual challenge. Eur J Heart Fail. 2012;14(2):130-137.

145. Suter TM, Procter M, van Veldhuisen DJ, et al. Trastuzumab-associated cardiac adverse effects in the herceptin adjuvant trial. J Clin Oncol. 2007;25(25):3859-3865.

146. Mackey JR, Clemons M, Coté MA, et al. Cardiac management during adjuvant trastuzumab therapy: recommendations of the Canadian Trastuzumab Working Group. Curr Oncol. 2008;15(1):24-35.
Breast Cancer: Targets and Therapy

\section{Publish your work in this journal}

Breast Cancer: Targets and Therapy is an international, peerreviewed open access journal focusing on breast cancer research, identification of therapeutic targets and the optimal use of preventative and integrated treatment interventions to achieve improved outcomes, enhanced survival and quality of life for the cancer patient.

\section{Dovepress}

View the full aims and scopes of this journal here. The manuscript management system is completely online and includes a very quick and fair peer-review system, which is all easy to use. Visit http:// www.dovepress.com/testimonials.php to read real quotes from published authors. 